\title{
Coordinated regulatory efforts needed to strengthen travel related immunization requirements against importation of infectious diseases
}

\author{
Y. Tony Yang ${ }^{\mathrm{a}, *}$, Julia E. Painter ${ }^{\mathrm{b}}$, Benjamin Mason Meier ${ }^{\mathrm{c}}$ \\ a Department of Health Administration and Policy, George Mason University, 4400 University Drive, Fairfax, VA 22030, United States \\ ${ }^{\mathrm{b}}$ Department of Global and Community Health, George Mason University, 4400 University Drive, Fairfax, VA 22030, United States \\ ${ }^{\mathrm{c}}$ Department of Public Policy, University of North Carolina, Chapel Hill, 103 Abernethy Hall, Chapel Hill, NC 27599-3435, United States
}

\section{Introduction}

Along with increases in international travel come increased opportunities for importation of infectious disease to the United States (U.S.). Many infectious diseases can lead to severe negative health outcomes for those infected, including disability and death, as seen recently through the importation of Ebola from West Africa and Zika from South America. Additionally, disease importation is a key contributing factor to the potential threat of emerging pathogens, such as novel strains of influenza, and the reemergence of vaccine-preventable diseases, such as measles [1]. In the U.S., most of the recent measles outbreaks originated from international travel [2], where the disease was brought into the U.S. by unvaccinated persons who were infected in other countries.

The public health threat caused by disease importation raises important questions about how governments regulate immunizations against infectious diseases as a means to achieve high vaccination rates, prevent disease outbreaks, and facilitate herd immunity. Laws and regulations play critical roles in limiting the spread of infectious diseases, with legal authorities essential to vaccination mandates or recommendations. Given the central contribution of international travel to disease importation in the U.S. and the heightened efforts to develop both Ebola and Zika vaccines, these threats and responses raise important and timely issues about the distribution of regulatory power regarding travel-related immunizations across global, federal, and state levels.

\section{Global level}

On the global level, there is no overarching system of required or necessary vaccines across all nations, even though the International Health Regulations (IHRs), the legal regime undergirding the global management of cross-border infectious disease threats, require all countries to establish minimum "core capacities" to

\footnotetext{
* Corresponding author at: Department of Health Administration and Policy, George Mason University, MS: 1J3, 4400 University Drive, Fairfax, VA 22030, United States.

E-mail addresses: ytyang@gmu.edu (Y.T. Yang), jpainte6@gmu.edu (J.E. Painter), bmeier@unc.edu (B.M. Meier).
}

detect, report, and respond to infectious disease outbreaks within their borders, and to immediately notify the World Health Organization (WHO) of any potential threat that may constitute a public health emergency of international concern (PHEIC) [2]. The WHO, the United Nations specialized agency with a mandate to direct and organize global health policy, has the constitutional authority to make international treaties, adopt legally binding regulations, and issue non-binding recommendations to member states. However, WHO's only legal requirement for international travel under the 2005 revision of the IHRs involves the yellow fever vaccine, which is required for entry into certain countries in sub-Saharan Africa and South America, as attested to by the International Certificate of Vaccination or Prophylaxis (ICV, or "Yellow Card") [3]. In the absence of WHO action to develop global vaccination regulations, national governments have come together with international organizations and public and private stakeholders to develop the 2014 Global Health Security Agenda (GHSA) [4], creating a global imperative for national governments to meet 11 GHSA “Action Packages" for preventing, detecting, and responding to infectious disease, including the development of laws at the national (or federal) level to prevent disease through enhanced immunization authority [4].

\section{Federal level}

In the U.S., regulatory authority over vaccinations is shared between states and the federal government. Following the Constitutional principal of separation of powers, the federal government regulates vaccinations concerning international travel and entry into the U.S. while individual states determine the regulations governing vaccines within their borders.

Currently, the only vaccination required by the federal government to travel abroad is the vaccination for yellow fever [5], which is required only for travel and entry into certain countries in subSaharan Africa and South America, in accordance with international obligations under WHO. The Centers for Disease Control and Prevention (CDC) also recommends that all U.S. travelers be up-to-date on routine vaccinations prior to international travel; however, none is legally required to travel abroad. Thus, there is no federal system in place to ensure that U.S. citizens are vaccinated against diseases 
before traveling abroad, no matter their prevalence in the overseas location; nor is there a federal system in place to prevent disease importation.

In the absence of visible symptoms of infection, reentry into the U.S. after traveling abroad usually does not require any additional immunizations or a quarantine period. Permanently immigrating to the U.S. does require proof of immunization for mumps, measles, rubella, polio, tetanus, diphtheria toxoids, pertussis, influenza, hepatitis $B$, and any other vaccine-preventable diseases recommended by the Advisory Committee for Immunization Practices (ACIP). If an immigrant is lacking a necessary vaccination, a civil surgeon will administer that vaccination upon entry examination [5].

The ACIP was established to "provide advice and guidance to the Director of the $\mathrm{CDC}$ regarding the most appropriate selection of vaccines and related agents for effective control of vaccine-preventable diseases in the civilian population" and to "provide advice for the control of diseases for which a vaccine is licensed in the U.S." [6]. For each recommended vaccine, the ACIP must (1) advise on population groups and/or circumstances in which a vaccine is recommended; (2) develop guidance on route, dose and frequency of administration of the vaccine; (3) provide recommendations on contraindications and precautions for use of the vaccine; (4) provide information on recognized adverse events; and (5) under appropriate circumstances, provide guidance for use of unlicensed vaccines [7]. Before making its recommendations, the ACIP must consider "disease epidemiology and burden of disease, vaccine efficacy and effectiveness, vaccine safety, economic analyses and implementation issues" [7].

\section{State level}

While the federal government proscribes the necessary immunizations for overseas travel, most of the power to regulate immunization falls to the states as part of their police powers. Although states do not regulate travel vaccines directly, the state public health authority does regulate the routine immunizations that are also recommended by CDC prior to international travel. This includes prescribing required vaccinations for student entry to school and university, for entry into childcare facilities, and for health care workers, doctors, nurses, and technicians. All Health Insurance Marketplace plans and most other private insurance plans cover most travel-related vaccines without charging a copayment or coinsurance when provided by an in-network provider [8].

Across states, however, there is variability regarding immunization laws and the processes by which vaccinations are mandated; as of July 1, 2016, 47 states allowed religious exemptions and 18 states allowed philosophical exemptions to vaccination [9]. Allowing non-medical exemptions can result in pockets of unvaccinated individuals susceptible to imported cases of disease, undercutting herd immunity and increasing the number of U.S. citizens who may import diseases by traveling internationally.

\section{Conclusion}

After Ebola and Zika vaccinations become available, the state's police power may be exercised to facilitate such vaccination rollouts, while the federal government can provide abundant guidance to states in this area, and global governance actors can seek to frame and harmonize laws for vaccination requirements and allocations. These varying layers of global, federal and state power over vaccinations leave many holes that allow for the importation and spread of vaccine-preventable diseases, such as measles, and novel pathogens in the U.S. In the absence of a global system governing travel-related immunizations or travel restrictions for ill passengers under the IHRs, each country must establish its own regulations. For the GHSA to accelerate progress toward a world safe and secure from infectious disease threats, national governments must establish the necessary legal framework to support immunization authorities. In the U.S., more could be done to prevent the importation of infectious diseases, particularly with respect to ensuring that U.S. citizens are vaccinated prior to traveling abroad. For example, the continued risk for importation of measles into the U.S. and occurrence of measles cases and outbreaks in communities with high proportions of unvaccinated persons highlight the need for measles vaccination for U.S. residents before overseas travel.

As it stands, the federal government proscribes immunizations necessary for overseas travel, yet the states regulate routine immunizations which are also recommended for international travel. Neither the federal nor state governments enforce compliance with travel vaccine recommendations, with the exception of yellow fever. Although there are contingency plans in place to employ vaccines as a medical countermeasure in the midst of a public health emergency, the effectiveness of these plans may be questioned in the absence of commensurate legal authorities. Currently, importation of various infectious diseases, such as measles, from both unvaccinated U.S. residents returning from travel abroad and foreign visitors seems unavoidable because no regulations are in effect requiring vaccination of these residents and visitors. A more coordinated regulatory effort across global, federal and state levels-balancing the public health benefits of vaccination against the costs to individual freedoms-could help ensure better compliance with vaccine recommendations and reduce opportunities for disease importation.

\section{Conflict of interest}

None.

\section{References}

[1] Centers for Disease Control and Prevention. Epidemiology and prevention of vaccine-preventable diseases. <http://www.cdc.gov/vaccines/pubs/pinkbook/ index.html>.

[2] World Health Organization. International Health Regulations. 2nd ed.; 2005 <http://www.who.int/ihr/9789241596664/en/>.

[3] World Health Organization. Yellow fever vaccination requirements and recommendations; malaria situation; and other vaccination requirements. <http://www.who.int/ith/ITH_country_list.pdf>.

[4] United States Department of Health and Human Services. The Global Health Security Agenda. <http://www.globalhealth.gov/global-health-topics/globalhealth-security/ghsagenda.html>.

[5] Centers for Disease Control and Prevention. Immunization laws. National Vaccine Program Office. <http://archive.hhs.gov/nvpo/law.htm\#Table>.

[6] Department of Homeland Security. Questions and answers, vaccination requirements. U.S. Citizenship and Immigration Services. <http://www. uscis.gov/news/questions-and-answers/vaccination-requirements>.

[7] Centers for Disease Control and Prevention. Advisory committee on immunization practices charter. <http://www.cdc.gov/vaccines/acip/committee charter.html, http://www.ncsl.org/research/health/school-immunizationexemption-state-laws.aspx>.

[8] Centers for Disease Control and Prevention. Finding and paying for vaccines <http://www.cdc.gov/vaccines/adults/find-pay-vaccines.html>.

[9] National conference of state legislatures. States with religious and philosophical exemptions from school immunization requirements. <http://www.ncsl.org/ research/health/school-immunization-exemption-state-laws.aspx>. 